INTERNATIONAL DESIGN CONFERENCE - DESIGN 2018

https://doi.org/10.21278/idc.2018.0209

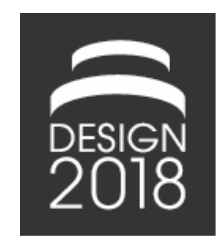

\title{
WORKSHOP METHOD FOR EARLY SUSTAINABLE PRODUCT DEVELOPMENT
}

\author{
J. Schulte and S. I. Hallstedt
}

\begin{abstract}
It is in the early phases of product development that most of a product's life-cycle sustainability impact is determined. This study presents a workshop method that has the purpose to support multi-disciplinary teams in sustainable product development, focusing on early phases. The workshop method aims to map the sustainability challenges and opportunities of a concept at an overarching level, utilizing backcasting from sustainability principles in three steps: create vision, assess current state, derive strategies. Testing and validation was done at two companies and with one academic group.
\end{abstract}

Keywords: sustainable design, early design phase, multi-/cross-/trans-disciplinary approaches, workshop, decision support

\section{Introduction}

A growing number of business leaders has started to acknowledge the implications of the inevitable transition of society towards a sustainable state in terms of both business opportunities and threats (Willard, 2012). Empirical studies indicate a positive effect of sustainable product innovation on overall company performance (Chen et al., 2006; Küçükoğlu and Pınar, 2015). The main company driving forces for investing in building capabilities for sustainable product innovation are increased competitiveness, legal requirements, brand and reputation, and employee motivation (Bansal and Roth, 2000; Dangelico and Pujari, 2010). Numerous tools and mechanisms exist that aim to facilitate companies' transition towards developing more sustainable products, including, for example, ISO standards, assessment tools, and eco-labelling. Still, companies are struggling with translating strategic commitment into operational action (Høgevold et al., 2014). Some of the main reasons are difficulties in how to make sustainability assessments in an efficient way and that companies lack a shared understanding of what sustainability means in the first place (Schulte and Hallstedt, 2017).

It is in the early phases of product development, where many sustainability related decisions are taken (Gaziulusoy et al., 2013). Thus, once a design concept is selected, most of the relevant sustainability attributes are fixed (Ny et al., 2008). However, despite increased sustainability knowledge and awareness, companies are facing difficulties when determining the goals and scope that effectively guide towards more sustainable products, due to the immaturity and complexity of sustainability integration in product development (Alblas et al., 2014).

A common and practical tool to utilize different stakeholders' expertise and knowledge in product development is innovation workshops. They are interactive meetings that follow a practical framework and structured approach for generating and discussing sustainable solutions to generate new concepts, or to make incremental changes for existing concepts (Hoffmann, 2007; Arnold, 2010). Workshop approaches are therefore suitable for sustainable innovation in early product development, because they 
can bring together multi-disciplinary teams that can work with both sustainability assessment and idea generation.

\subsection{Aim and purpose}

The purpose of this study is to provide product development and manufacturing companies with a workshop method that supports multi-disciplinary teams in sustainable product development (SPD) in early phases. To this end, the following research questions (RQs) are addressed:

- RQ1: What approaches do currently exist in the scientific literature that use workshops for sustainable product development and what are their main characteristics and challenges?

- RQ2: How can a workshop method be utilised to effectively and efficiently integrate a strategic sustainability perspective in the early phases of product development, allocating sustainability challenges and opportunities of a concept at an overarching level?

\subsection{Outline}

In the following Section 2, the context and some main tools and concepts within the area of sustainable product development are described. After that, the research approach is presented in Section 3. This is followed by Section 4 containing the results and discussion of the study, starting with the mapping of existing scientific publications guided by RQ1, also including the identification of characteristics and challenges of existing methods. The second part of the results provides a description of the development and testing of the novel SPD workshop method, as well as an overview of its main steps, in line with RQ2. Finally, Section 5 concludes by reflecting on the value and contribution of the new SPD workshop method in the light of previous work within the area.

\section{Background}

Several approaches and tools have been developed to assist in more sustainable product generation. For example, several eco-design tools in forms of matrices, guidelines, and checklists, such as ABCAnalysis, the MECO Method, LiDS-Wheel, and Strategy List (e.g. Byggeth and Hochschorner, 2006; Poulikidou, 2016), as well as Life Cycle Assessment (LCA) (ISO, 2006). Recent studies have also concluded that despite the existence of decision support methods and tools for sustainability consideration in product development, the implementation of these support tools is low (Zetterlund et al., 2016; Schulte and Hallstedt, 2017). Furthermore, many support tools are limited to taking one or two dimensions of sustainability into account, rather than including a full sustainability perspective, covering ecological, social, and economic aspects.

Applied research in operational tools and methods that support SPD, (i.e. a strategic sustainability perspective is integrated and implemented into the early phases of the product innovation process, including life cycle thinking) aims to strengthen businesses to overcome this challenge, in addition to increasing the companies' competitiveness. Several generic support tools have been developed for SPD, summarized in e.g. Salari and Bhuiyan (2016), and Buchert et al. (2014), which aim to support development teams in integrating sustainability in the early development stages and to give guidance in decision making. However, some challenges are pointed out for these methods: combination and integration within the product development process; inclusion of a whole life cycle perspective; only a few are validated in companies; and, not based on a clear definition of what the sustainability dimensions mean. Furthermore, few support tools include a long-term time perspective, which makes it harder to take actions today for issues that might occur in the future, while the solution is still operational (Hallstedt et al., 2013b).

The framework for strategic sustainable development (FSSD) is building a base for some approaches in the area of SPD. The FSSD has been developed, peer-reviewed, used, tested and refined for over 20 years (Broman and Robèrt, 2017) with many applications by different researchers (Ny et al., 2008; Schöggl et al., 2017). The framework is based on backcasting, which means imagining success in the future and then looking back at the current situation through the lens of that success definition, and to explore ways to reach that success (Dreborg, 1996; Vergragt and Quist, 2011). The FSSD utilizes firstorder principles, which describe the root mechanisms for unsustainability, to derive a vision that can be 
used as success definition. The sustainability principles (SPs) state that "organizations who want to move into a sustainable society should not contribute to systematically increasing: ... (SP1) concentrations of substances extracted from the Earth's crust, (SP2) ...concentrations of substances produced by society, (SP3) ... degradation by physical means, and, in that society (SP4) people are not subject to conditions that systematically undermine their capacity to meet their needs." The social sustainability principle has been recently developed into five distinct principles (SP4-SP8): "people are not subject to structural obstacles to: health; influence; competence; impartiality; and, meaning-making (Missimer, 2015).

Many of the previously introduced methods are either too broad to help in any concrete decision making, demand resources beyond the organization's capabilities, do not include a full socio-ecological sustainability perspective, or require very detailed data that is not available in early product development phases. Accordingly, there is a need for an easy-to-use method to incorporate sustainability aspects during the very early phases of the product development process. Therefore, this study presents an approach, which combines the concept and elements of the FSSD with a multidisciplinary workshop setup.

\section{Method}

A literature review was conducted prior to the development of the workshop method to map existing research that addresses support tools for sustainability integration in the early phases of product development, focusing on workshop approaches.

The review included journal and conference articles published between 2005 and February 2017. The following four databases were selected: Web of Science (reference database), Scopus (reference database), Emerald (article database), and the Design Society database (article database). Topic search (title, abstract, and author key words) was conducted in all four databases, using a search string with the following key words and applicable synonyms: sustainability, eco-design, workshop, support tool, product innovation, early design, life-cycle, guided questions, backcasting, and roadmap. In line with the purpose of this article, the review was restricted to papers that explicitly utilize a workshop or guided questions approach as tools to integrate sustainability in the early product development phases. The resulting papers were examined for adequacy and relevance for the article's purpose. Article selection and analysis were guided by Blessing and Chakrabarti (2009) and Karlsson et al. (2009): the selection process started by reading the titles of about 1400 papers in the selected databases. Dependent on the degree of relevance, abstract and key words were read. At this stage, around 140 papers were explored further by reading their introduction and conclusions. Based on an assessment of the articles' relevance, the following 12 papers were identified for full review, also including the applied method, purpose and results: Arnold, 2017; Byggeth et al., 2007; Gaziulusoy et al., 2013; Hallstedt, 2009; Hallstedt, et al., 2013a; Hallstedt et al., 2015a; Hoffmann, 2007; Leroy et al., 2015; Lloveras, 2013; Mestre and Vogtlander, 2013; Saidani et al., 2016; Schöggl et al., 2017. Conventional qualitative content analysis (Hsieh and Shannon, 2005) was deployed and key attributes of each source were documented.

Based on findings from the literature review, complemented with experiences and advise from sustainability experts and academics working closely with industry, a sustainable product development workshop method was proposed. Its main purpose is to identify sustainability challenges and opportunities of a concept at an overarching level. Thereby, it would assist product development teams in achieving a fast and easy overview of the sustainability implications of a concept, early in the development process. The workshop approach is based on backcasting from the sustainability principles of the FSSD. The detailed workshop method is explained in Section 4.2. The method was validated and tested at two large multinational product development and manufacturing case companies, located in Sweden. Company A is a manufacturer of jet engine components in the aerospace industry, while Company $\mathrm{B}$ is developing and manufacturing construction machines, see Table 1 . The testing at the companies focused on evaluating the practical applicability of the workshop method in industry. In addition, the workshop was carried out with an international academic group, mostly from members of the Sustainable Design Special Interest Group within the Design Society, at the 14th International Design Conference in 2016. 
Table 1. Two large multinational product development and manufacturing companies tested the workshop method

\begin{tabular}{c|ccc} 
Company & Industry & Turnover, k€ & Employees \\
\hline A & Aerospace & 800000 & 2000 \\
B & $\begin{array}{c}\text { Construction } \\
\text { machines }\end{array}$ & 2750000 & 4000
\end{tabular}

\section{Results and discussion}

\subsection{Literature review}

Hoffmann (2007) introduced the INNOCOPE approach, constituting of three workshops at different phases of the product development process. It includes participants from both company employees and consumers, with a three months' period between each of the workshops. The first workshop includes product introduction and idea generation, the second workshop addresses idea evaluation and selection, and the third workshop is dedicated for prototype assessment and marketing ideas. From a sustainability perspective, the approach focuses mainly on climate change and consumers' prior knowledge of the subject. The results of the study showed that even though the INNOCOPE process contained climate change measures as a theme, climate impact was not a criterion that participants took into consideration when generating ideas.

Hallstedt et al. (2013b) presented an approach for assessing the sustainability of material handling through a workshop with employees at an aerospace company in addition to a value chain partner. Based on the workshop, a modelling and simulation approach to assess sustainability and value consequences was proposed. In a similar approach, Sustainability Assessment and Value Evaluation method (SAVE), qualitative sustainability assessment techniques including sustainability guided questions are combined with quantitative Net Present Value (NPV) analysis. The method allocates sustainability hotspots and clarifies potential sustainability consequences of a new concept (Hallstedt et al., 2015b). The SAVE method can support a design team to build NPV scenarios based on possible changes for some identified sustainability parameters. In a workshop session, the design team estimates the likeliness for the changes to happen, which can support a decision in the early stages of product development.

Gaziulusoy et al. (2013) presented a scenario method with a workshop as an operational tool, with the aim of helping product development teams to incorporate sustainability issues into their decision making. The workshop consists out of two separate full days, one week apart from each other. In this method, backcasting from scenarios is utilized. However, it can be challenging for a large group to agree on a desired future scenario (Broman and Robèrt, 2017). In the same year, Lloveras (2013) proposed an approach to analyse some environmental sustainability aspects, mainly the consumption of energy and/or water, in the conceptual product design phase. The approach includes a guide of five questions for the design team, focusing on more environmental-friendly consumption alternatives. Leroy et al. (2015) created two methods, Combineval and Geneval, which were tested in a one day session including groups of experts from academia and industry, to turn elementary ideas into environmental-friendly concepts.

Some proposed workshops require facilitation through a sustainability or eco-design expert, such as the work presented by Saidani et al. (2016). In the study, an eco-innovation workshop is proposed, which includes stakeholder identification and an environmental assessment, i.e. LCA. This workshop results in defining environmental targets. Schöggl et al. (2017) developed a checklist for sustainable product development in early phases that includes 49 questions covering a full life cycle perspective, linked to the sustainability principles introduced earlier. However, a sustainability expert is needed to guide the use of the checklist and to achieve the best results. Byggeth et al. (2007) presented a Method for Sustainable Product Development (MSPD), which integrates socio-ecological aspects of sustainability in product development. The method utilizes backcasting from sustainability principles. Furthermore, it includes a set of guiding questions derived from those principles and the product life cycle. Based on 
MSPD application, product developers showed a desire to have a sustainability expert to offer a quick overview of the relevant product sustainability aspects. Therefore, the Template for Sustainable Product Development (TSPD) was introduced, based on some generic key questions, with a sustainability expert facilitating the application of the tool (Ny et al., 2008).

Based on this literature review, a number of challenges for the current workshop approaches to integrate a sustainability perspective in the early phases of product development was identified. Existing methods (i) demand an expert to guide the design team through the different steps; (ii) are dependent on the development and implementation of simulation models to derive scenarios; (iii) are time demanding, i.e. many hours or days are needed to complete the workshop and get a result; (iv) need detailed data that usually is not available in the early stages; or, (v) do not cover all dimensions of sustainability, i.e. the economic, social and ecological dimensions. The development of the new SPD workshop was guided by the aim to overcome these challenges.

\subsection{Sustainable product development workshop method}

To overcome the challenge of developing and agreeing on scenarios, and to include a full sustainability perspective, the SPD workshop approach is based on backcasting from sustainability principles, in line with the FSSD, as presented in the introduction section. This is combined with a product life cycle perspective from raw material acquisition and production; manufacturing (including re- manufacturing); packaging and distribution; usage and maintenance (including re-use); upgrading (recycling), to end of life.

The backcasting approach is illustrated in Figure 1. The workshop process consists out of three steps, based on the ABCD-method of the FSSD (Broman and Robèrt, 2017): first, a vision of a sustainable product is created. Second, the current situation and its implications from a sustainability perspective are assessed. In the last step, ideas and strategies are derived for how the gap between the vision and the current state can be bridged. Guiding questions were provided for the "to be" session and templates with guiding examples of typical sustainability aspects for each life cycle phase were used by the participants for the "as is" session, see Appendix.

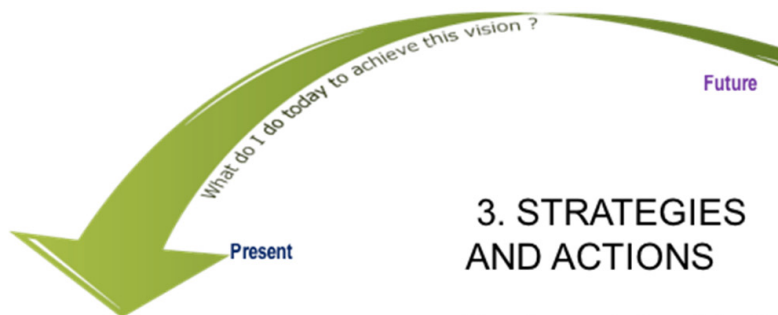

2. AS IS

What are some main sustainability challenges and strengths of the current product?

- Identify some sustainability gaps and strengths throughout the product life cycle. (30 min)

Figure 1. Illustration of the SPD workshop methodology

The workshop was tested at the two case companies from the construction vehicles and aerospace industries. Considering the complexity of many products, their value chains, and sustainability impacts, the group of workshop participants should ideally be cross functional and include roles like product developers, purchasers, after market staff, product planners, environmental engineers, etc. No prior expertise on sustainability is required, but the results benefit from the team's knowledge and understanding of the product system and the life-cycle. The number of participants varied between the two cases. In the aerospace company, 10 employees from the research and development, production, 
and procurement departments participated in the workshop. In the construction vehicles manufacturer company, 5 employees took part in the workshop, mainly from product development and environment teams. The purpose in the vehicles case company was to identify sustainability challenges of a construction machine product, and then to identify improvement possibilities throughout the product life cycle. The workshop with the aerospace case company aimed at allocating sustainability challenges and gaps relevant to a turbine exhaust structure, and how the product life cycle could be improved.

The workshops took approximately two and half hours in total, starting with 30 minutes introduction, followed by three consecutive sessions (see below), where each session requires 30 minutes, and a 1520 minutes concluding discussion. Dependent on the complexity of the investigated product and the size of the group, the workshop steps could be prolonged. However, the purpose of the method is not to provide exhaustive and highly detailed results, but rather to give a quick overview of hots-pots in the early design phases.

\subsubsection{To-be session}

In the first session, participants are divided into groups of 3-5, who start with imagining success in the future, defined by a vision of a sustainable product in a sustainable future society. In this step, the participants describe their vision of a desired and ideal future product design, "To be", without restrictions, and write down their ideas in a 10 minute' time frame. This session is guided by prepared questions that were derived from the SPs and the product lifecycle, thereby combining a full sustainability perspective and life cycle thinking. Previous research showed how guiding questions can help participants in their idea generation, without limiting them, like for example checklists (Byggeth et al., 2007; Ny et al., 2008). Next, the groups are asked to discuss and describe a sustainable product, and to answer the questions in a paragraph form within 15 minutes. The final 5 minutes are utilized for the groups to briefly read and present the ideas to each other. The five questions to guide the groups in this session are presented in Table 2 below, in addition to examples of answers extracted from the conducted workshop with case Company B, addressing the design of a wheel loader.

\section{Table 2. Guided questions for the "To be" session with answers sample}

\begin{tabular}{|c|c|}
\hline Guiding questions & Examples of answers \\
\hline $\begin{array}{l}\text { What are the materials to be used in a sustainable } \\
\text { product version? }\end{array}$ & $\begin{array}{l}\text { - Replace the rubber and plastic in the interior parts } \\
\text { - Switch to using ceramic bearings, which } \\
\text { eliminates the use of oil } \\
\text { - Utilize nanotechnology }\end{array}$ \\
\hline $\begin{array}{l}\text { Which suppliers are associated with a sustainable } \\
\text { product? (e.g. working conditions) }\end{array}$ & $\begin{array}{l}\text { - Prioritizing suppliers with long-term thinking } \\
\text { - Selecting local suppliers to minimize } \\
\text { transportation, and boost the local business }\end{array}$ \\
\hline $\begin{array}{l}\text { How could a sustainable product be produced? } \\
\text { How are the working conditions? Consider e.g. } \\
\text { chemicals, health and safety, emissions to air, } \\
\text { water, and soil }\end{array}$ & $\begin{array}{l}\text { - Reducing noise and vibrations in production, } \\
\text { resulting in better working environment for } \\
\text { employees } \\
\text { - Urban mining } \\
\text { - Reducing chemical use and keeping the parts } \\
\text { clean, to lengthen the product life span. }\end{array}$ \\
\hline $\begin{array}{l}\text { How is the sustainable product used and } \\
\text { maintained? (e.g. life-time, noise, secure / robust } \\
\text { design) }\end{array}$ & $\begin{array}{l}\text { - Utilizing steam and solar cells. } \\
\text { - Be } 100 \text { percent independent of fossil fuels } \\
\text { - Reuse bearings, less virgin materials use }\end{array}$ \\
\hline $\begin{array}{l}\text { How can the product be recycled, reused, re- } \\
\text { manufactured for as long as possible? }\end{array}$ & $\begin{array}{l}\text { - Resell the product, or make use of the scrap } \\
\text { - Remanufacturing of all modules }\end{array}$ \\
\hline
\end{tabular}




\subsubsection{As-is session}

In the "As is" session, which takes about 45 minutes, the participants are again divided into new groups. Depending on the number of participants and the group size, each group is assigned two or three life cycle phases. People who work within procurement, materials, and production should participate in the raw materials and production phases group, while people with more knowledge about the use and end of life phases should join the respective group. In this session, backcasting from the future vision to the present is applied, mainly by investigating what the organization is doing today to achieve the vision. Consequently, the "As is" situation is reached, where problems are defined, along with challenges, knowledge level, and needs. Participants are asked to start by giving examples of the various product sustainability implications of the current product that they know about, spending about 10 to 20 minutes. Afterwards, the present situation description is guided by defined questions over the product life cycle for another 10 to 20 minutes, covering the three environmental sustainability principles (SP 1, 2, and 3), and social aspects (SPs 4 to 8). In addition, the economic dimension is assessed, based on a maturity model developed by Baumgartner and Ebner (2010). Finally, each group presents their results, in total about 10 minutes. Examples of the used guiding questions in this session are shown in Table 3, together with a sample of answers from the vehicles manufacturer workshop.

Table 3. Guided questions for the "As is" session with answers sample

\begin{tabular}{|c|c|c|c|c|}
\hline Life cycle phase & Guiding question & $\begin{array}{l}\text { Ecological dimension } \\
\text { (SP1-3) }\end{array}$ & $\begin{array}{l}\text { Social dimension } \\
\text { (SP4-8) }\end{array}$ & $\begin{array}{l}\text { Economic } \\
\text { dimension }\end{array}$ \\
\hline Raw materials & $\begin{array}{l}\text { What sustainability } \\
\text { challenges have } \\
\text { current materials? }\end{array}$ & $\begin{array}{l}\text { - Zinc, Nickel, } \\
\text { Cadmium }\end{array}$ & $\begin{array}{l}\text { - Metal mining } \\
\text { personnel } \\
\text { - Chemicals that } \\
\text { could have an } \\
\text { effect on } \\
\text { employees' health } \\
\text { and safety }\end{array}$ & $\begin{array}{l}\text { - Environmental- } \\
\text { friendly purchasing } \\
\text { choices regardless } \\
\text { of the price }\end{array}$ \\
\hline Production & $\begin{array}{l}\text { What sustainability } \\
\text { challenges have } \\
\text { current production } \\
\text { processes? }\end{array}$ & $\begin{array}{l}\text { - Fumes from } \\
\text { chemicals } \\
\text { - Spilling of } \\
\text { machining liquids that } \\
\text { should be well } \\
\text { handled }\end{array}$ & $\begin{array}{l}\text { - Risk of accidents } \\
\text { with high noise } \\
\text { levels } \\
\text {-Project Stress } \\
\text { - Solvents effects. }\end{array}$ & -Risk analysis \\
\hline $\begin{array}{l}\text { Usage and } \\
\text { maintenance }\end{array}$ & $\begin{array}{l}\text { What sustainability } \\
\text { challenges has the } \\
\text { current design in } \\
\text { usage and } \\
\text { maintenance? }\end{array}$ & $\begin{array}{l}\text {-Fossil fuels and } \\
\text { lubricants } \\
\text { - Batteries for hybrids, } \\
\text { such as Lithium }\end{array}$ & $\begin{array}{l}\text { - Possible safety } \\
\text { issues in the usage } \\
\text { stage if it is sold for } \\
\text { a second life and } \\
\text { the company is not } \\
\text { in charge for } \\
\text { maintenance } \\
\text { anymore. }\end{array}$ & $\begin{array}{l}\text { - Different markets } \\
\text { and their view of } \\
\text { the value of } \\
\text { sustainability (e.g. } \\
\text { some countries are } \\
\text { not interested in } \\
\text { clean machines) }\end{array}$ \\
\hline End of life & $\begin{array}{l}\text { What sustainability } \\
\text { challenges has a } \\
\text { wheel loader in the } \\
\text { EoL phase? }\end{array}$ & $\begin{array}{l}\text { - Complex design that } \\
\text { is difficult to recycle } \\
\text { - No monitoring of } \\
\text { how a customer } \\
\text { handles oil, etc. }\end{array}$ & $\begin{array}{l}\text {-Recycling of } \\
\text { electronic parts } \\
\text { take place where } \\
\text { there are poor } \\
\text { social and } \\
\text { environmental } \\
\text { conditions, due to } \\
\text { cost cutting } \\
\text { strategies. }\end{array}$ & $\begin{array}{l}\text { - More complex } \\
\text { machines with } \\
\text { shorter life span }\end{array}$ \\
\hline
\end{tabular}




\subsubsection{Strategies session}

The purpose of the "Strategies" session is to generate ideas for how to move from the "As is" situation to the "To be" vision. While the "To be" step focuses on the requirements and characteristics of a sustainable product without constraints, the "Strategies" session is about finding concrete solutions and paths that lead towards the desired "To be" state, considering preconditions, challenges and opportunities that were identified in the "As is" step. In case some "To be" elements identified by the participants turn out to be strategies as well, it is easy for the team to pick up those elements in the "Strategies" session again, now being able to relate it to the "As is" situation. For 30 minutes, the same groups as from the second session generate ideas and suggestions to achieve the vision of reaching more sustainable solutions. No templates or guiding questions are provided for this step, in order to leave room for the participants' own experience and creativity. Also, the applications of the SPD workshop showed that participants get many solution ideas in the course of the first two steps, making it easy for them to get started on the "Strategies" session without further guidance.

Some of the suggested actions by participants in the workshops were:

- Bring in sustainability competences early in the concept and design phase.

- Include a sustainability impact review as a gate-stopper in the early phases.

- More expertise and knowledge in chemicals, their implications and what could replace them.

- Performing remanufacturing activities locally.

- Increase modular design to ease upgrading.

- Create more service-oriented business models.

- Focus the designing efforts towards both life cycle costing and sustainability.

- Increase the collaboration regarding sustainability with other actors in the value chain.

- Investigate new manufacturing technologies, e.g. additive manufacturing, to minimise waste and enable easier repair.

- Include a sustainability perspective in material selection studies.

\subsection{Evaluation of the SPD workshop method}

A third workshop was conducted at the Design Conference in 2016, as an academic review to evaluate the approach. It included 35 participants, all researchers within the product design community. Participants were divided into 4 groups working in parallel on a jeans product, to analyse the relevant sustainability potentials and challenges.

The feedback following the workshop highlighted some aspects that are important for a fruitful outcome. Participants emphasized the importance of having more stakeholder interaction, e.g. other companies in the value chain, legislators, customers etc. Stakeholders need to have different backgrounds, to better reveal the environmental, social and economic aspects, stressing the importance of involving a multidisciplinary team with different areas of expertise.

The participants found the conducted workshop to be a quick and an efficient way to make a sustainability assessment. Even though the workshops were facilitated by sustainability researchers in the test cases, the presence of a sustainability expert is not a necessary requirement. Instead, a company's own environmental manager or written instructions could likely replace the introduction and expert facilitation of the workshop. This adds to the simplicity and ability of the method to be used by different companies. Furthermore, guiding questions in addition to the provided examples for each life cycle phase, were perceived as user friendly and easy to understand by the participants. However, to simplify the communication of results between product development teams and other levels of the company, such as management, several suggestions have been provided, e.g. to use more graphical illustrations of the results, and to use different charts and methods to collect suggested ideas. This is important to make sure that the results of the workshop actually will be applied and make a difference in practice.

Potential limitations of the SPD workshop method are that the quality of results is dependent on the level of knowledge of the participants, both in relation to sustainability and to the life cycle and value chain of the product. Gathering a multi-disciplinary team with complementary areas of expertise is therefore a key success factor. Also, with this method, it can be difficult to compare products or concepts that are rather similar, as it only provides a qualitative assessment. However, this is not the main purpose, 
as the SPD workshop rather focuses on creating a quick overview of sustainability hot-spots at an overarching level. It could then be complemented through, for example, traditional LCA to make a more detailed, quantitative assessment of the hot-spots, similar to the method presented by Ny et al. (2006). Further development for the assessment approach is needed. In this work, economic aspects were covered based on a model by Baumgartner and Ebner (2010). Possible future work could consider whether the Future Fit Business Benchmark (Future-Fit Foundation, 2017) could be used to provide a more detailed and sustainability related base for analysis. Also, it would be important to investigate ways for how to integrate the SPD workshop with existing company processes and tools.

\section{Conclusions}

The main purpose of this paper was to develop a workshop method that can support design teams in integrating a sustainability perspective in the early phases of product development. To this end, existing scientific publications in the field were reviewed. Based on identified challenges with existing methods, key elements of the framework for strategic sustainable development, i.e. backcasting from first-order sustainability principles, were combined with a product life-cycle perspective. In this way, a novel SPD workshop method was derived and tested in two large product development and manufacturing companies, and in a group of academic experts. The main advantages of the new approach are that it (i) is easy to use and not dependent on the presence of a sustainability expert; (ii) includes a full life cycle perspective to avoid sub-optimisation; (iii) proofed to be applicable in the early phases of product development, where information is rough and incomplete; (iv) considers also social sustainability issues, which otherwise has been a less developed area within design for sustainability; (v) provides an efficient and quick way to map the main sustainability hot-spots of a product or concept; (vi) is strategic through the application of backcasting from sustainability principles, which has been shown to be an efficient way to find smart stepping stones and out of the box solutions (Broman and Robèrt, 2017).

The workshop results provide design teams with a clear overview of sustainability opportunities and challenges associated with a product or concept at an overarching level. Both at the case companies and in the academic group, the application of the method did not only result in product related improvement ideas, but also organizational changes and specific process improvements, some of which are prerequisites for making changes in the product. Several participants at the companies also pointed out the value of the workshop method for the soft side of sustainable design, through raising awareness, creating a sense of ownership, and triggering discussions around sustainability in a product design context.

The main contribution of the suggested workshop method is providing a tool that could be used by multidisciplinary teams to explore different sustainable solutions, through utilizing sustainability innovation thinking on an overall level. This workshop method is part of a model based support (MBE) toolbox (Jaghbeer et al., 2017), which includes several support tools and methods to be used in the different stages of sustainable product development. For sufficient guidance and more detailed assessment, it is advised to use the other support tools in combination to this workshop. Future work intends to develop the SPD workshop method further, and to combine it with other sustainability innovation workshops. The economic sustainability assessment also needs clarification and deserves further attention.

\section{Acknowledgments}

Many thanks to Yasmeen Jaghbeer for contributing to this research. Financial support from the Knowledge Foundation in Sweden is gratefully acknowledged. Sincere thanks to the industrial research partners.

\section{References}

Alblas, A.A., Peters, K. and Wortmann, J.C. (2014), "Fuzzy sustainability incentives in new product development", International Journal of Operations \& Production Management, Vol. 34 No. 4, pp. 513-545. https://doi.org/10.1108/IJOPM-10-2012-0461

Arnold, M. (2010), "Stakeholder Dialogues for Sustaining Cultural Change", International Studies of Management and Organization, Vol. 40 No. 3, pp. 61-77. https://doi.org/10.2753/IMO0020-8825400304

Bansal, P. and Roth, K. (2000), "Why Companies Go Green: A Model of Ecological Responsiveness", The Academy of Management Review, Vol. 43 No. 4, pp. 717-736. https://doi.org/10.2307/1556363 
Baumgartner, R.J. and Ebner, D. (2010), “Corporate sustainability strategies: Sustainability profiles and maturity levels", Sustainable Development, Vol. 18 No. 2, pp. 76-89. https://doi.org/10.1002/sd.447

Blessing, L.T.M. and Chakrabarti, A. (2009), DRM, a Design Research Methodology, Springer, London. https://doi.org/10.1007/978-1-84882-587-1

Broman, G.I. and Robèrt, K.-H. (2017), "A Framework for Strategic Sustainable Development”, Journal of Cleaner Production, Vol. 140 No. 1, pp. 17-31. https://doi.org/10.1016/j.jclepro.2015.10.121

Buchert, T., Kaluza, A., Halstenberg, F.A., Lindow, K., Hayka, H. and Stark, R. (2014), "Enabling product development engineers to select and combine methods for sustainable design", Procedia CIRP, Vol. 15, pp. 413-418. https://doi.org/10.1016/j.procir.2014.06.025

Byggeth, S. and Hochschorner, E. (2006), "Handling trade-offs in Ecodesign tools for sustainable product development and procurement", Journal of Cleaner Production, Vol. 14 No. 15-16, pp. 1420-1430. https://doi.org/10.1016/j.jclepro.2005.03.024

Byggeth, S., Broman, G. and Robèrt, K.H. (2007), “A method for sustainable product development based on a modular system of guiding questions", Journal of Cleaner Production, Vol. 15 No. 1, pp. 1-11. https://doi.org/10.1016/j.jclepro.2006.02.007

Chen, Y.S., Lai, S.B. and Wen, C.T. (2006), "The influence of green innovation performance on corporate advantage in Taiwan", Journal of Business Ethics, Vol. 67 No. 4, pp. 331-339. https://doi.org/10.1007/s10551006-9025-5

Dangelico, R.M. and Pujari, D. (2010), "Mainstreaming green product innovation: Why and how companies integrate environmental sustainability", Journal of Business Ethics, Vol. 95 No. 3, pp. 471-486. https://doi.org/10.1007/s10551-010-0434-0

Dreborg, K.H. (1996), "Essence of backcasting”, Futures, Vol. 28 No. 9, pp. 813-828. https://doi.org/10.1016/S0016-3287(96)00044-4

Future-Fit Foundation (2017), Future-Fit Business Benchmark - Methodology Guide, Release 2 v2.0.1.

Gaziulusoy, A.I., Boyle, C. and McDowall, R. (2013), "System innovation for sustainability: A systemic doubleflow scenario method for companies", Journal of Cleaner Production, Vol. 45, pp. 104-116. https://doi.org/10.1016/j.jclepro.2012.05.013

Hallstedt, S. (2009), "Strategic decisions guided by tools and methods based on sustainability questions", ICORD 09: Proceedings of the 2nd International Conference on Research into Design, Bangalore, India, January 79, 2009, pp. 113-120.

Hallstedt, S., Thompson, A.W., Isaksson, O., Larsson, T.C. and Ny, H. (2013a), “A Decision Support Approach for Modeling Sustainability Consequences in an Aerospace Value Chain", Proceedings of the ASME 2013 International Design Engineering Technical Conferences \& Computers and Information in Engineering Conference, pp. 1-10. https://doi.org/10.1115/DETC2013-12975

Hallstedt, S.I., Bertoni, M. and Isaksson, O. (2015), “Assessing Sustainability and Value of Manufacturing Processes: A case in the aerospace industry", Journal of Cleaner Production, Vol. 108 No. A, pp. 169-182. https://doi.org/10.1016/j.jclepro.2015.06.017

Hallstedt, S.I., Thompson, A.W. and Lindahl, P. (2013b), "Key elements for implementing a strategic sustainability perspective in the product innovation process", Journal of Cleaner Production, Vol. 51, pp. 277288. https://doi.org/10.1016/j.jclepro.2013.01.043

Hoffmann, E. (2007), “Consumer integration in sustainable product development”, Strategic Direction, Vol. 24 No. 1, pp. 322-338.

Høgevold, N.M., Svensson, G., Wagner, B., Petzer, D.J., Klopper, H.B. et al. (2014), “Sustainable business models: Corporate reasons, economic effects, social boundaries, environmental actions and organizational challenges in sustainable business practices", Baltic Journal of Management, Vol. 9 No. 3, pp. 357-380. https://doi.org/10.1108/BJM-09-2013-0147

Hsieh, H.F. and Shannon, S.E. (2005), “Three Approaches to Qualitative Content Analysis", Qualitative Health Research, Vol. 15 No. 9, pp. 1277-1288. https://doi.org/10.1177/1049732305276687

ISO (2006), ISO 14040:2006: Environmental Management - Life Cycle Assessment - Principles and Framework.

Jaghbeer, Y., Hallstedt, S.I., Larsson, T. and Wall, J. (2017), "Exploration of Simulation-Driven Support Tools for Sustainable Product Development", Procedia CIRP, Vol. 64, pp. 271-276. https://doi.org/10.1016/j.procir.2017.03.069

Karlsson, C., Croom, S., Forza, C., Voss, C., Åhlström, P. et al. (2009), Researching Operations Management, Routledge, New York. https://doi.org/10.4324/9780203886816

Küçükoğlu, M.T. and Pınar, R.İ. (2015), "Positive Influences of Green Innovation on Company Performance", Procedia - Social and Behavioral Sciences, Vol. 195, pp. 1232-1237. https://doi.org/10.1016/j.sbspro.2015.06.261 
Leroy, Y., Tyl, B., Vallet, F., Leroy, Y., Tyl, B. et al. (2015), "Environmental evaluation of ideas in early phases : a challenging issue for design teams", The 20th International Conference on Engineering Design (ICED 15), pp. 117-126.

Lloveras, J. (2013), "Conceptual Design Guide for Energy and”, ICED13: 19th International Conference on Engineering Design, pp. 1-10.

Mestre, A. and Vogtlander, J. (2013), "Eco-efficient value creation of cork products: An LCA-based method for design intervention", Journal of Cleaner Production, Vol. 57, pp. 101-114. https://doi.org/10.1016/j.jclepro.2013.04.023

Missimer, M. (2015), Social Sustainability within the Framework for Strategic Sustainable Development Merlina Missimer, PhD thesis, Blekinge Institute of Technology, Karlskrona.

Ny, H., Hallstedt, S., Robèrt, K.H. and Broman, G. (2008), "Introducing templates for sustainable product development: A case study of televisions at the Matsushita Electric Group", Journal of Industrial Ecology, Vol. 12 No. 4, pp. 600-623. https://doi.org/10.1111/j.1530-9290.2008.00061.X

Ny, H., MacDonald, J.P., Broman, G., Yamamoto, R. and Robert, K.-H. (2006), "Sustainability Constraints as System Boundaries: An Approach to Making Life-Cycle Management Strategic", Journal of Industrial Ecology, Vol. 10 No. 1-2, pp. 61-77. https://doi.org/10.1162/108819806775545349

Poulikidou, S. (2016), Assessing Design Strategies for Improved Life Cycle Environmental Performance of Vehicles, PhD thesis, Royal Institute of Technology.

Saidani, M., Cluzel, F., Leroy, Y. and Auclaire, A. (2016), "Time-efficient eco-innovation workshop process in complex system industries", Proceedings of the DESIGN 2016 / 14th International Design Conference, Dubrovnik, Croatia, May 16-19, 2016, Vol. DS 84, The Design Society, Glasgow, pp. 483-492.

Salari, M. and Bhuiyan, N. (2016), "A proposed approach to improve current sustainable product development", Journal of Industrial and Production Engineering, Vol. 33 No. 5, pp. 297-307. https://doi.org/10.1080/21681015.2016.1172122

Schöggl, J.P., Baumgartner, R.J. and Hofer, D. (2017), "Improving sustainability performance in early phases of product design: A checklist for sustainable product development tested in the automotive industry", Journal of Cleaner Production, Vol. 140, pp. 1602-1617. https://doi.org/10.1016/j.jclepro.2016.09.195

Schulte, J. and Hallstedt, S. (2017), "Challenges and Preconditions to Build Capabilities for Sustainable Product Design”, Proceedings of ICED'17 / the 21st International Conference on Engineering Design, Vancouver, Canada, August 21-25, 2017, Vol. 1, The Design Society, Glasgow, pp. 1-10.

Vergragt, P.J. and Quist, J. (2011), "Backcasting for sustainability: Introduction to the special issue", Technological Forecasting and Social Change, Vol. 78 No. 5, pp. 747-755. https://doi.org/10.1016/j.techfore.2011.03.010

Willard, B. (2012), "The New Sustainability Advantage: Seven Business Case Benefits of a Triple Bottom Line", International Journal of Sustainability in Higher Education, Vol. 14 No. 4. https://doi.org/10.1108/ijshe.2013.24914daa.012

Zetterlund, H., Hallstedt, S. and Broman, G. (2016), "Implementation potential of sustainability-oriented decision support in product development", Proceedings of the 26th CIRP Design Conference, Stockholm. https://doi.org/10.1016/j.procir.2016.05.011 


\section{Appendix}

Table 4. Guiding questions and examples for the "To be" session

\section{\begin{tabular}{l|l} 
Guided questions & Examples of sustainability aspects
\end{tabular}}

\begin{tabular}{l|l}
\hline $\begin{array}{l}\text { What materials does the sustainable company product } \\
\text { consist of? }\end{array}$ & Metals, composites, chemicals \\
\hline $\begin{array}{l}\text { Which suppliers are available for the sustainable } \\
\text { company product? }\end{array}$ & Working conditions \\
\hline $\begin{array}{l}\text { How is the sustainable company product produced? } \\
\text { How is the working environment in the production? }\end{array}$ & Chemicals, health and safety, emissions, water \\
\hline $\begin{array}{l}\text { How is the sustainable company product used and } \\
\text { maintained? }\end{array}$ & Secure, robust design \\
\hline $\begin{array}{l}\text { How can the company product be recycled for as } \\
\text { long as possible? }\end{array}$ & Recycling, reuse, remanufacturing
\end{tabular}

Table 5. Guiding questions and examples of typical sustainability aspects for each life cycle phase, to be used in the "As is" session

\begin{tabular}{|c|c|c|}
\hline Life cycle phase & Guiding question & Examples of sustainability aspects \\
\hline Raw materials & $\begin{array}{l}\text { What sustainability } \\
\text { challenges have } \\
\text { current materials? }\end{array}$ & $\begin{array}{l}\text { Ecological: Metal alloys, chemical used, land use } \\
\text { Social: Conflict materials, hazardous chemicals, influence, } \\
\text { competence development, non-discrimination, stress, injuries, } \\
\text { accidents } \\
\text { Economic: Supplier network }\end{array}$ \\
\hline Production & $\begin{array}{l}\text { What sustainability } \\
\text { challenges have } \\
\text { current production } \\
\text { processes? }\end{array}$ & $\begin{array}{l}\text { Ecological: Waste, spill, scrap, chemical used, fossil-based } \\
\text { energy source, clean water usage } \\
\text { Social: Hazardous chemicals, influence, competence } \\
\text { development, non-discrimination, stress, injuries, accidents } \\
\text { Economic: Human capital, knowledge sharing }\end{array}$ \\
\hline $\begin{array}{l}\text { Usage and } \\
\text { maintenance }\end{array}$ & $\begin{array}{l}\text { What sustainability } \\
\text { challenges has the } \\
\text { current design? }\end{array}$ & $\begin{array}{l}\text { Ecological: Clean processes, fuel efficiency, weight of product } \\
\text { Social: Noise, safety issues, competence development, non- } \\
\text { discrimination, stress, injuries, accidents } \\
\text { Economic: Innovation, Best available technology }\end{array}$ \\
\hline End of life & $\begin{array}{l}\text { What sustainability } \\
\text { challenges has the } \\
\text { product at the EoL? }\end{array}$ & Ecological: Possibilities to disassembly \\
\hline
\end{tabular}

Jesko Schulte, M.Sc.

Blekinge Institute of Technology, Department of Strategic Sustainable Development

Stora Hammar 138, 37042 Torhamn, Sweden

Email: jesko.schulte@bth.se 